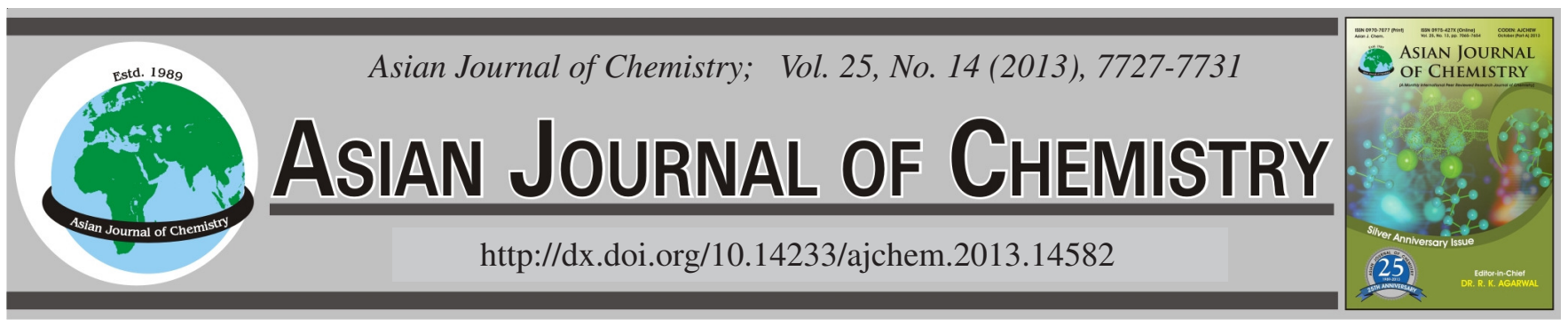

\title{
Characteristics of Photosynthetic Performance, Antioxidant Capacity and Nutrient Concentration of Tibetan Wild Barley in Response to Aluminium Stress
}

\author{
Huaxin Dai ${ }^{1}$, Wasim Ibrahim ${ }^{1}$, Wei-Te Zheng ${ }^{1}$, Muhammad Dawood ${ }^{1}$, Xiaoyan He $^{1}$, \\ Jing ZhaO ${ }^{1}$, Guo-Ping Zhang ${ }^{2}$, Chengdao Li and Fei-Bo Wu ${ }^{1, *}$
}

\begin{abstract}
${ }^{1}$ Department of Agronomy, College of Agriculture and Biotechnology, Zijingang Campus, Zhejiang University, Hangzhou 310058, P.R. China ${ }^{2}$ Department of Agriculture, Government of Western Australia, South Perth, Australia

*Corresponding author: Tel/Fax: +86 571 88982827; E-mail: wufeibo@zju.edu.cn
\end{abstract}

\begin{abstract}
Greenhouse hydroponic experiments were conducted to investigate genotypic differences in response to aluminium stress among two contrasting Tibetan wild barley genotypes XZ16 (aluminium tolerant) and XZ61 (aluminium sensitive) and cv. Dayton (aluminium tolerant) and as affected by anion inhibitor of niflumic acid (NIF). The results showed that Tibetan wild barley XZ16 exhibited superior aluminium-resistantce/tolerance reflected by significant low aluminium uptake and malondialdehyde (MDA) accumulation and an enhancement in net photosynthetic rate, stomatal conductance, transpiration rate and maintaining relatively lower intercellular $\mathrm{CO}_{2} \mid$ concentration $\left(\mathrm{C}_{\mathrm{i}}\right)$ under $100 \mu \mathrm{M}$ aluminium in contrast to XZ61 and Dayton. Meanwhile, XZ16 exhibited higher P, S, Ca and Mg contents in roots and shoots under aluminium stress compared with XZ61 and Dayton. Moreover, activities of catalase (CAT) andascorbate peroxidase (APX) in ROS scavenging systems play an important role in alleviating aluminium induced oxidative stress in XZ16. Shoot CAT in XZ16 was markedly enhanced after $15 \mathrm{~d}$ aluminium treatment, while markedly reduced in XZ61. APX of XZ16 showed special changing pattern against the other two genotypes i.e. root/shoot APX increased after $6 \mathrm{~h}$ aluminium treatment and niflumic acid (Al + NIF) significantly enhanced shoot APX activity in XZ16, but not in XZ61 and Dayton. After 10 days aluminium exposure, shoot APX in XZ16 was kept similar value to its control, but in XZ61 and Dayton was sharply reduced relative to controls.
\end{abstract}

Key Words: Aluminium toxicity, Antioxidant enzymes, Mineral elements, Photosynthetic performance, Tibetan wild barley.

\section{INTRODUCTION}

Aluminum is considered as one of the major factors limiting crop productivity in acid soil and is highly toxic to plant growth $^{1}$. Aluminum stress results in nutrient deficiency and elevation of lipid peroxidation and reactive oxygen species $(\mathrm{ROS})^{2,3}$. However, different patterns of Al toxicity on ROSscavenging enzymes were found ${ }^{4}$. Therefore, it is imperative to determine the changes in Al-induced oxidant stress and antioxidant systems in order to verify the hypothesis that some antioxidants besides their function in detoxification, may also be sensitive targets of Al toxicity in plants.

Barley (Hordeum vulgare L.) is one of the most Al sensitive cereal species ${ }^{5}$. Acid soils greatly restricted cultivation and expansion of barley in many agricultural areas ${ }^{6}$. Tibetan annual wild barley, one of progenitors of cultivated barley, is rich in genetic diversity ${ }^{7}$. Recently, we identified two Tibetan wild barley XZ16 and XZ61 (H. vulgare L. ssp. spontaneum) showing high tolerance and sensitivity to Al stress, respectively ${ }^{8}$. However, the physiological responses such as photosynthesis rate, antioxidant enzymes, lipid peroxidation production or nutrient element content in Tibetan wild barley to Al stress have not been investigated and compared with elite $\mathrm{Al}$ tolerant barley cultivars.

The present study was conducted to evaluate genotypic difference in two contrasting wild barley genotypes XZ16 (Al tolerant) and XZ61 (Al sensitive) and an Al tolerant cv. Dayton by comparing photosynthetic parameters, active oxygen metabolism and nutrients in plants exposing to Al stress.

\section{EXPERIMENTAL}

Greenhouse hydroponic experiments were carried out at Huajiachi campus, Zhejiang University, Hangzhou, China. Two Tibetan annual wild barley XZ16 and XZ61 (acid/Al- tolerant and sensitive genotypes, respectively) and a cv. Dayton (Al tolerant) were used in the experiments. Healthy seeds were surface sterilized and germinated as described by Dai et al. ${ }^{8}$. Seven day old uniform healthy seedlings were transplanted to $4.5 \mathrm{~L}$ containers in a greenhouse at $20 \pm 5^{\circ} \mathrm{C}$. The composition of the basic nutrient solution (BNS) was the same as $\mathrm{Wu}$ et $a l .{ }^{9}$. All hydroponic experiments employed a completely randomized block design with three replicates (14 plants per 
replicate) and the solution was continuously aerated and replaced daily.

Experimental design: Twenty day old seedlings were exposed to BNS solution containing 0 or $50 \mu \mathrm{M} \mathrm{AlCl}{ }_{3}$ in the presence and absence of $10 \mu \mathrm{M}$ anion channel inhibitor of niflumic acid. After $6 \mathrm{~h}$ exposure to Al treatment, seedlings were washed with distilled water and separated into roots and upper second fully expanded leaves for determination of MDA content and activity of antioxidant enzymes.

As to time course of $\mathrm{Al}$ treatment experiment, seedlings of seven days after transplanting were exposed to BNS solution containing 0 (control) or $100 \mu \mathrm{M} \mathrm{AlCl}_{3}$ (Al treatment) at $\mathrm{pH}$ 4.3. Root and leaf samples were collected after 1, 5, 10, 15 days $\mathrm{Al}$ addition and lipid peroxidation (MDA) and antioxidant enzymes activities were measured. After 15 days $\mathrm{Al}$ addition, photosynthetic parameters were determined and plants were harvested, separated into roots and shoots. Root and shoot samples were dried in an oven for $48 \mathrm{~h}$ at $70{ }^{\circ} \mathrm{C}$ and then weighted for determination of $\mathrm{Al}$ and mineral element contents.

Photosynthetic measurements: Measurements of net photosynthetic rate $\left(\mathrm{P}_{\mathrm{n}}\right)$, stomatal conductance $\left(\mathrm{g}_{\mathrm{s}}\right)$, intercellular $\mathrm{CO}_{2}$ concentration $\left(\mathrm{C}_{\mathrm{i}}\right)$ and transpiration rate $(\mathrm{Tr})$ were carried out on the up second leaves of five plants from both control and treatments of each genotype using an LI-6400 photosynthesis system (Li-Cor, Lincoln, NE, USA).

Determination of antioxidant enzyme activity and lipid peroxidation: Root and leaf extracts were prepared in $50 \mathrm{mM}$ Tris-HCl buffer ( $\mathrm{pH}$ 7.4) by grinding with a pestle and mortar on ice. The homogenate was centrifuged at $8500 \mathrm{~g}$ for $10 \mathrm{~min}$ at $4{ }^{\circ} \mathrm{C}$ and then the supernatants were used for enzyme and lipid peroxidation assays. SOD, POD and CAT activities and MDA content were determined according to Wu et al. ${ }^{9}$. Total APX activity was determined as previously described ${ }^{10}$.

Mineral analysis: Dried root and shoot samples were ground and digested in an acid mixture $\left(\mathrm{HNO}_{3}: \mathrm{HClO}_{4}=4: 1\right.$, $\mathrm{v} / \mathrm{v})$ at $150{ }^{\circ} \mathrm{C}$ for $6 \mathrm{~h}$. Contents of $\mathrm{Al}$, macro- and micronutrient elements were determined using an inductively coupled plasma atomic emission spectrometry (ICP/AES) (IRIS/AP optical emission spectrometer, Thermo Jarrel Ash, San Jose, CA).

Statistical analysis: The statistical analyses were performed with the using the Data Processing System (DPS) Software Package ${ }^{11}$. Statistical analysis was carried out by ANOVA using Duncan's multiple range test to evaluate statistical significance.

\section{RESULTS AND DISCUSSION}

Photosynthetic characteristics: Compared with control, photosynthetic rate and stomatal conductance in plants under $100 \mu \mathrm{M} \mathrm{Al}$ increased by 14.1 and $24.3 \%$, respectively in XZ16, while decreased by 39.3 and $25.2 \%$ in XZ61 and no significant change in Dayton (Fig. 1A-B). $\mathrm{C}_{\mathrm{i}}$ of XZ16 and Dayton was not affected upon Al stress, whereas XZ61 showed a significant $(p<0.05)$ Al-induced increase of $13.8 \%$ (Fig. 1C). Furthermore, transpiration rate of Al-treated XZ16 was significantly increased by $27.7 \%(p<0.05)$, however, no significant changes were found in XZ61 and Dayton when compared with their controls (Fig. 1D).

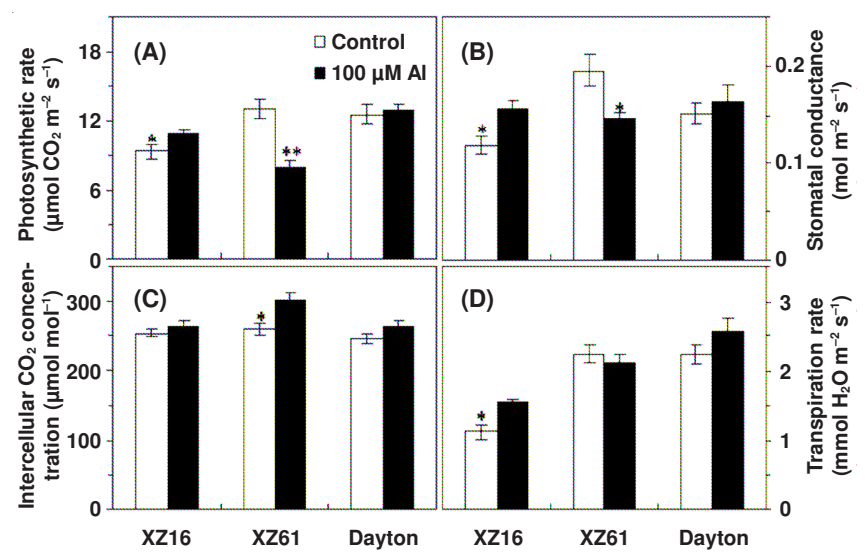

Fig. 1. Photosynthetic rate (A), stomatal conductance (B), intercellular $\mathrm{CO}_{2}$ concentration (C) and transpiration rate (D) in leaves of three barley genotypes grown in basic nutrient solution without ( $\square$, control) and with (, $\mathrm{Al}) 100 \mu \mathrm{M} \mathrm{Al}$ for 15 days at $\mathrm{pH}$ 4.3. Data are means \pm SD $(\mathrm{n}=5)$. Significant differences between $\mathrm{Al}$ treatment and control are indicated by $* *(p<0.01)$ and $*(p<0.05)$.

Effects of Al and anion channel inhibitor niflumic acid on ROS-scavenging enzymes and lipid peroxidation: Aluminium stress and niflumic acid $(\mathrm{Al}+\mathrm{NIF})$ induced a genotype depended effect on antioxidant enzyme activities in roots and leaves (Fig. 2). After $6 \mathrm{~h} \mathrm{Al}$ treatment, root CAT, APX and SOD activities in XZ16 increased by $57.6,23.7$ and $18.3 \%$, respectively and CAT in Dayton by $58.6 \%(p<0.01)$, while no significant change in XZ61; niflumic acid significantly decreased root

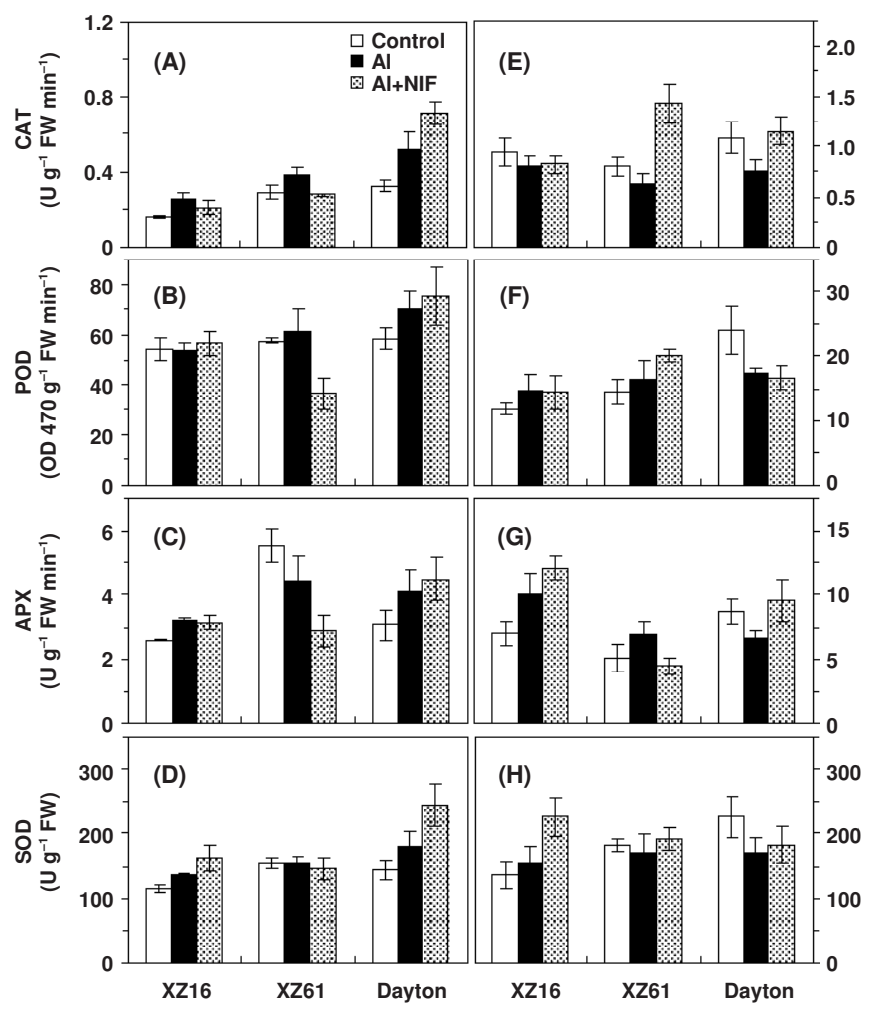

Fig. 2. Effect of Al treatment and anion channel inhibitor niflumic acid (NIF), on CAT, POD, SOD and APX activities in roots (A, B, C and D) and leaves (E, F, G and H). Seedlings were exposed to $50 \mu \mathrm{M}$ $\mathrm{AlCl}_{3}$ containing $0.5 \mathrm{mM} \mathrm{CaCl} 2$ at $\mathrm{pH} 4.3$ in the presence and absence of $10 \mu \mathrm{M}$ of niflumic acid for $6 \mathrm{~h}$. Data are means \pm SD (n =3). Control, $\mathrm{Al}$, niflumic acid and $\mathrm{Al}+\mathrm{NIF}$ represent basal solution without $\mathrm{Al}$ (BS, $0.5 \mathrm{mM} \mathrm{CaCl} 2, \mathrm{pH} 4.3$ ), BS+50 $\mu \mathrm{M} \mathrm{AlCl}_{3}$ and $\mathrm{BS}+50 \mu \mathrm{M} \mathrm{AlCl}{ }_{3}+\mathrm{NIF}$, respectively 
CAT and APX activities in XZ61, while increased in Dayton. In shoots, APX activity under niflumic acid condition was significantly enhanced in XZ16 and Dayton (c.f. 20.2 and $55.2 \%$, respectively), whereas reduced by $35.3 \%$ in XZ61 over Al treatment (Fig. 2). Meanwhile, XZ16 under Al stress exhibited $45.3 \% / 24.8 \%$ in roots and $53.9 \% / 22.3 \%$ in shoots lower MDA content than XZ61/Dayton (Fig. 3A-B).
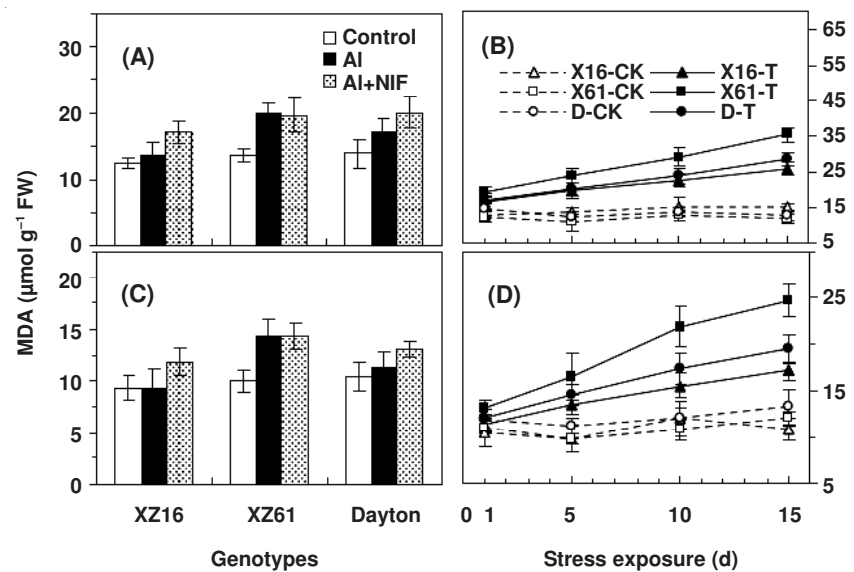

Fig. 3. MDA content in roots (A, C) and shoots (B, D) of XZ16, XZ61 and Dayton. (A, B), Effect of anion channel inhibitor niflumic acid on MDA content after $6 \mathrm{~h}$ exposure to $50 \mu \mathrm{M} \mathrm{AlCl}_{3}$ in the presence and absence of $10 \mu \mathrm{M}$ of niflumic acid. Control, $\mathrm{Al}$ and $\mathrm{Al}+\mathrm{NIF}$ represent basal solution without $\mathrm{Al}\left(\mathrm{BS}, 0.5 \mathrm{mM} \mathrm{CaCl}_{2}\right.$ at $\mathrm{pH} 4.3$ ), $\mathrm{BS}+50 \mu \mathrm{M} \mathrm{AlCl} l_{3}$ and $\mathrm{BS}+50 \mu \mathrm{M} \mathrm{AlCl}+\mathrm{NIF}$, respectively. (C, D), Time course experiment, in BNS (control, open symbols) and 100 $\mu \mathrm{M}$ Al treatment (treatment, filled symbols). XZ16-CK, XZ61-CK, Dayton-CK and XZ16-T, XZ61-T and Dayton-T represent XZ16, XZ61, Dayton under control (BNS) and Al stress (BNS+100 $\mu \mathrm{M}$ $\left.\mathrm{AlCl}_{3}\right)$ conditions, respectively. Data are means $\pm \mathrm{SD}(\mathrm{n}=3)$

Time course of lipid peroxidation and ROS-scavenging enzymes in response to Al stress: Overall, the four antioxidant enzymes in roots of three genotypes were gradually increased with $100 \mu \mathrm{M} \mathrm{Al}$ duration compared with control, especially on day 5 and day 10. In shoots, CAT, POD, APX and SOD of three genotypes varied over the 15 days Al exposure (Fig. 3). Compared with control, CAT activity on day 10 in XZ61 were significantly reduced by $38 \%$, while no significant change shown in XZ16 and Dayton. Whereas on day 15, CAT in XZ16 were markedly enhanced $(p<0.01)$ by $61.8 \%$ under $\mathrm{Al}$ treatment, but no significant change shown in XZ61 and Dayton. APX activity in XZ16 showed no statistic difference compared with the control on day 10 under Al stress, but in XZ61 and Dayton reduced $(p<0.01)$ by 83.1 and $70.7 \%$, respectively. Content of MDA was elevated by Al stress up to 2.24- and 1.75- fold compared with control over 15 days in roots and leaves of XZ61, respectively, which showed significantly ( $p<$ 0.01) higher increase of MDA content than XZ16 (c.f. 1.48and 1.33- fold, respectively) and Dayton (c.f. 1.67- and 1.33fold, respectively) (Fig. 3C-D).

Macro- and micro-nutrients: Compared with control 1 ( $\mathrm{pH} 4.3$ without $\mathrm{Al}$ ), $100 \mu \mathrm{M} \mathrm{Al}$ led to a dramatic increase ( $p$ $<0.01$ ) in Al concentration by 3.0-, 5.1- and 4.0- folds in roots and by 1.4-, 2.3- and 1.5- folds in leaves for XZ16, XZ61 and Dayton, respectively, while XZ16 showed the lowest Al value in roots and leaves (Table-1). In roots, 15 days exposure to $\mathrm{pH}$ 4.3 without $\mathrm{Al}$ significantly increased $\mathrm{S}$ content in XZ16 by $17.0 \%$ compared with $\mathrm{pH} 6.0$ without $\mathrm{Al}$. Root P under Al treatment for XZ16 was not affected, but in XZ61 and Dayton decreased significantly by 37.8 and $20.5 \%$, respectively. Al stress reduced Mn content in XZ16, increased in XZ61, but not affected on Dayton. Moreover, $\mathrm{Al}$ exposure resulted in significant decline $(p<0.05)$ in macro- and micro-nutrients $\mathrm{Ca}, \mathrm{Mg}, \mathrm{Fe}, \mathrm{Zn}$ and $\mathrm{Cu}$ in roots and $\mathrm{Ca}, \mathrm{Mg}$ and $\mathrm{Mn}$ in leaves of all three genotypes (Table-1). Shoot $\mathrm{P}$ was markedly decreased by $18.2 \%$ in XZ61, but not affected in XZ16 and Dayton when exposed to $\mathrm{Al}$ stress. Meanwhile, Al stress increased $\mathrm{S}$ content, no effect on $\mathrm{Zn}$ in shoots of all three genotypes.

$\mathrm{Ohki}^{12}$ demonstrated that $\mathrm{Al}$ stress induced decline of photosynthetic rate and transpiration rate in a C3 (Triticum aestivum) and a C4 plant (Sorghum bicolour). In our study, XZ16 exhibited superior Al-tolerance as reflected by enhancement of photosynthetic parameters such as photosynthetic rate, stomatal conductance and transpiration rate and maintaining relatively lower $\mathrm{C}_{\mathrm{i}}$ in contrast to XZ61 and Dayton (Fig. 1). Shamsi et al..$^{13}$ suggested that part of photosynthetic rate reduction can be attributed to a significant reduction in shoot $\mathrm{K}, \mathrm{Mg}$ and $\mathrm{Fe}$, which is partly in accordance to our results which even showed a genotypic difference, i.e., shoot $\mathrm{K}, \mathrm{Mg}$, $\mathrm{P}$ and $\mathrm{Ca}$ concentration was higher in XZ16 under Al stress

TABLE-1

EFFECT OF $100 \mu \mathrm{M}$ Al TREATMENT ON ROOT Al AND MINERAL ELEMENTS CONTENTS IN XZ16, XZ61 AND DAYTON. SEEDLINGS (13 days OLD) WERE GROWN IN BASIC NUTRIENT SOLUTION (BNS) FOR $7 \mathrm{~d}$ AND THEN EXPOSED TO $100 \mu \mathrm{M}$ Al FOR 15 days IN BNS (pH 4.3)

\begin{tabular}{|c|c|c|c|c|c|c|c|c|c|c|c|}
\hline \multirow{2}{*}{ Genotype } & \multirow{2}{*}{ Treatment } & $\mathrm{Al}$ & $\mathrm{Fe}$ & $\mathrm{Mn}$ & $\mathrm{Zn}$ & $\mathrm{Cu}$ & $\mathrm{P}$ & $\mathrm{K}$ & $\mathrm{Ca}$ & $\mathrm{Mg}$ & $\mathrm{S}$ \\
\hline & & \multicolumn{5}{|c|}{$\mu \mathrm{g} / \mathrm{g}$} & \multicolumn{5}{|c|}{$\mathrm{mg} / \mathrm{g}$} \\
\hline \multirow{3}{*}{ XZ16 } & CK 1 (pH 6.0) & 154.2 & 645.7 & 358.9 & 332.8 & 243.5 & 5.79 & 14.4 & 2.14 & 3.61 & 3.37 \\
\hline & CK 2 (pH 4.3) & 151.2 & 628.3 & 308.4 & 272.1 & 140.2 & 5.34 & 14.1 & 2.02 & 3.12 & 4.71 \\
\hline & $\mathrm{pH} 4.3+\mathrm{Al}$ & 638.5 & 503.8 & 152.8 & 241.5 & 83.2 & 4.77 & 17.5 & 1.68 & 1.91 & 5.51 \\
\hline \multirow{3}{*}{ XZ61 } & CK 1 (pH 6.0) & 157.5 & 745.1 & 363.7 & 441.6 & 231.3 & 5.88 & 16.1 & 2.23 & 3.75 & 4.35 \\
\hline & CK 2 (pH 4.3) & 145.8 & 689.1 & 263.6 & 337.1 & 125.5 & 5.56 & 15.9 & 2.07 & 3.47 & 4.57 \\
\hline & $\mathrm{pH} 4.3+\mathrm{Al}$ & 883.5 & 451.2 & 392.8 & 358.4 & 148.4 & 3.46 & 19.3 & 1.31 & 1.62 & 4.15 \\
\hline \multirow{3}{*}{ Dayton } & CK 1 (pH 6.0) & 152.9 & 743.2 & 366.1 & 377.9 & 229.2 & 5.53 & 18.6 & 2.12 & 3.04 & 4.48 \\
\hline & CK 2 (pH 4.3) & 134.5 & 579.9 & 281.4 & 304.6 & 115.6 & 5.42 & 18.3 & 1.94 & 2.55 & 4.69 \\
\hline & $\mathrm{pH} 4.3+\mathrm{Al}$ & 674.3 & 418.4 & 286.3 & 288.3 & 94.5 & 4.31 & 23.0 & 1.70 & 1.61 & 4.75 \\
\hline \multirow{3}{*}{\multicolumn{2}{|c|}{$\begin{array}{l}\text { LSD0. } 05 \text { between varieties } \\
\text { LSD0.05 between treatments } \\
\text { Interaction }\end{array}$}} & 103.2 & 56.4 & 47.4 & 34.5 & 17.3 & 0.91 & 3.21 & 0.31 & 0.56 & 0.67 \\
\hline & & 88.9 & 39.7 & 22.5 & 27.6 & 14.1 & 0.71 & 2.17 & 0.19 & 0.30 & 0.54 \\
\hline & & $* *$ & $* *$ & $*$ & $*$ & $*$ & $* *$ & $* *$ & $*$ & $*$ & $*$ \\
\hline
\end{tabular}


than that of XZ61. Meanwhile, XZ16 exhibits relatively higher concentration of chlorophyll content based on leaf area than the control as demonstrated by SPAD values (chlorophyll-meter readings $)^{8}$. However, the influence of $\mathrm{Al}$ on photosynthesis is probably indirect, through the inhibition of ion uptake or rootshoot transport, concentrations of nutrients essential for chlorophyll synthesis and maintenance ${ }^{14}$.

Catalase or APX showed to be one of major roles in combating oxidative damage induced by $\mathrm{Al}^{15}$. We previously demonstrated that niflumic acid, highly inhibited ATPase activity and citrate release in Al sensitive XZ61 under Al stress, thus inhibited activity of antioxidant enzymes (CAT, POD and APX) under niflumic acid condition in XZ61 also could be related to its Al sensitivity. Furthermore, enhancement of CAT and APX activities might be one of the strategies of Al tolerance in XZ16. In addition, Yin et al. ${ }^{16}$ demonstrated that lipid peroxide-derived aldehydes, formed downstream of reactive oxygen species, injured root cells directly. In this study, we found that the highest MDA content existed in XZ61 (Fig. 3), indicating that $\mathrm{Al}$ induced lipid peroxide might be related to its severe root cell damage, inhibition of root length and decline of mineral. Thus, MDA content could be an indicator of $\mathrm{Al}$ sensitivity to distinguish Al tolerant/sensitive genotypes.

Among the mineral elements, significantly higher concentrations of $\mathrm{P}, \mathrm{Mg}$ and $\mathrm{Ca}$ were detected in roots and shoots of Al-resistant XZ16 and Dayton than those of sensitive genotype XZ61 (Tables 1 and 2). Arsenic to phosphorus, it was proposed that the formation of Al-P complexes in roots of $\mathrm{Al}$ resistant genotypes helps to reduce cytosolic $\mathrm{Al}$ accumulation and accelerate active transport of Al-P complex to vacuoles ${ }^{17}$. In addition, $\mathrm{Mg}$ was efficient in alleviating Al-inhibited root elongation and stimulating citrate efflux ${ }^{18,19}$. When it comes to increase of $\mathrm{K}$ uptake, it can be correlated with expansion of cell volume and cell elongation ${ }^{20}$. Dawood et al. ${ }^{21}$ reported that $\mathrm{S}$ could improve depressed CAT and uptake of $\mathrm{P}, \mathrm{Ca}$ and $\mathrm{Mg}$, simultaneously reduce $\mathrm{Al}$ and MDA accumulation, elevate photosynthetic performance in barley. Furthermore, severe chlorosis was found in some leaves of XZ61 subjecting to Al treatment (data not shown), which might be due to Al-induced interference in the uptake and use of $\mathrm{Fe}$ and $\mathrm{Cu}$ for maintenance of chlorophyll ${ }^{20}$. The relatively high $\mathrm{Mn}$ content in $\mathrm{Al}$ sensitive

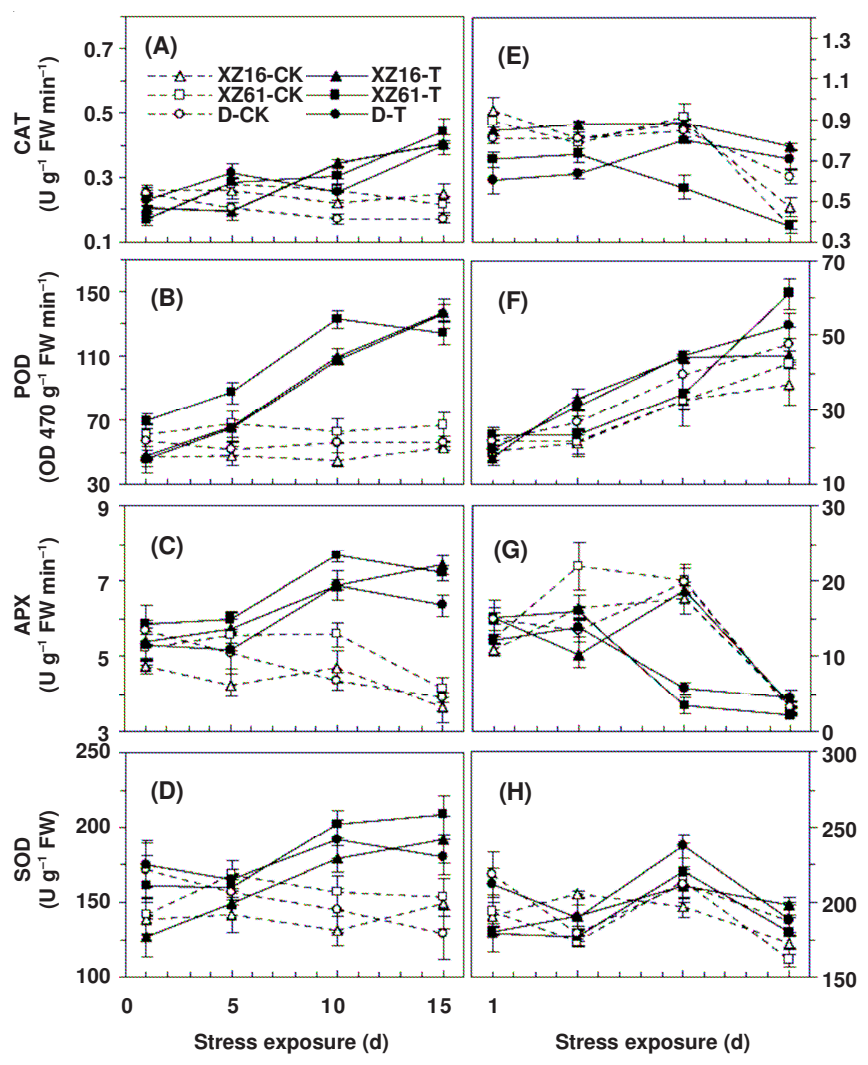

Fig. 4. Control (open symbols) and $100 \mu \mathrm{M}$ Al treatment (filled symbols) on CAT, POD, SOD and APX activities in roots (A, B, C and D) and leaves (F, G, H and I). Seedlings of XZ16, XZ61 and Dayton were grown in BNS for 15 days in the presence (Treatment, T) or absence (Control, CK) of $100 \mu \mathrm{M} \mathrm{AlCl}_{3}$ at $\mathrm{pH}$ 4.3. XZ16-CK, XZ61CK, Dayton-CK and XZ16-T, XZ61-T, Dayton-T represent XZ16, XZ61, Dayton under control (BNS) and Al stress (BNS+100 $\mu \mathrm{M}$ $\left.\mathrm{AlCl}_{3}\right)$ conditions, respectively. Data are means $\pm \mathrm{SD}(\mathrm{n}=3)$

plant revealed a negative correlation between high Mn contents and $\mathrm{Al}$ tolerance in barley ${ }^{2}$.

\section{Conclusion}

In summary, $\mathrm{Al}$ stress affects the rate of uptake and distribution of certain nutrients, consequently would be responsible for mineral deficiencies or imbalance and depression of plant growth. Tibetan wild barley XZ16 shows potential as an

TABLE-2

EFFECT OF $100 \mu \mathrm{M}$ Al TREATMENTS ON SHOOT Al AND MINERAL ELEMENT CONTENTS

IN THREE BARLEY GENOTYPES. SEEDLINGS (13 days OLD) WERE GROWN IN BASIC NUTRIENT SOLUTION (BNS) FOR 7 days AND THEN EXPOSED TO $100 \mu \mathrm{M}$ Al FOR 15 days IN BNS (pH 4.3)

\begin{tabular}{|c|c|c|c|c|c|c|c|c|c|c|c|}
\hline \multirow{2}{*}{ Genotype } & \multirow{2}{*}{ Treatment } & $\mathrm{Al}$ & $\mathrm{Fe}$ & $\mathrm{Mn}$ & $\mathrm{Zn}$ & $\mathrm{Cu}$ & $\mathrm{P}$ & $\mathrm{K}$ & $\mathrm{Ca}$ & $\mathrm{Mg}$ & $\mathrm{S}$ \\
\hline & & \multicolumn{5}{|c|}{$\mu \mathrm{g} / \mathrm{g}$} & \multicolumn{5}{|c|}{$\mathrm{mg} / \mathrm{g}$} \\
\hline \multirow{3}{*}{ XZ16 } & CK 1 (pH 6.0) & 68.2 & 252.5 & 71.2 & 153 & 20.1 & 6.43 & 49.9 & 4.79 & 3.47 & 3.68 \\
\hline & $\mathrm{CK} 2(\mathrm{pH} 4.3)$ & 57.4 & 268.6 & 64.3 & 135.3 & 20.4 & 6.22 & 41.1 & 4.23 & 3.01 & 3.24 \\
\hline & $\mathrm{pH} 4.3+\mathrm{Al}$ & 135.2 & 221.3 & 44.8 & 125.8 & 19.7 & 6.17 & 47.8 & 2.89 & 1.99 & 4.04 \\
\hline \multirow{3}{*}{ XZ61 } & CK 1 (pH 6.0) & 65.5 & 283.1 & 84.5 & 166.5 & 28.3 & 6.32 & 47.5 & 4.44 & 2.05 & 3.48 \\
\hline & CK 2 (pH 4.3) & 57.8 & 238.1 & 67.8 & 144.7 & 27.5 & 5.97 & 41.5 & 4.21 & 3.23 & 3.17 \\
\hline & $\mathrm{pH} 4.3+\mathrm{Al}$ & 189.7 & 185.7 & 46.6 & 122.1 & 21.2 & 4.81 & 40.5 & 1.97 & 1.38 & 3.77 \\
\hline \multirow{3}{*}{ Dayton } & CK 1 (pH 6.0) & 70.1 & 229.0 & 94.7 & 124.5 & 27.4 & 6.05 & 45.8 & 4.27 & 3.34 & 3.55 \\
\hline & CK 2 (pH 4.3) & 59.4 & 189.3 & 79.8 & 102.5 & 20.9 & 5.62 & 40.6 & 3.46 & 2.88 & 3.24 \\
\hline & $\mathrm{pH} 4.3+\mathrm{Al}$ & 148.3 & 199.4 & 70.4 & 100.7 & 22.5 & 5.29 & 47.3 & 2.53 & 1.77 & 4.08 \\
\hline \multicolumn{2}{|c|}{ LSD0.05 between varieties } & 17.6 & 21.8 & 7.4 & 17.2 & 4.8 & 0.79 & 5.14 & 0.53 & 0.36 & 0.48 \\
\hline \multicolumn{2}{|c|}{ LSD0.05 between treatments } & 15.3 & 15.3 & 6.1 & 14.9 & 3.5 & 0.55 & 4.42 & 0.42 & 0.26 & 0.26 \\
\hline \multicolumn{2}{|l|}{ Interaction } & $* *$ & $* *$ & $*$ & NS & $*$ & $* *$ & $* *$ & $* *$ & $* *$ & $*$ \\
\hline
\end{tabular}

$* p<0.05, * * p<0.01, \mathrm{NS}=$ Non significance. 
'Al-excluder' with low Al uptake and translocation and retains higher $\mathrm{P}, \mathrm{S}, \mathrm{Ca}$ and $\mathrm{Mg}$ content in root/shoot of plants under $\mathrm{Al}$ stress. Al stress induced MDA increment and decreased photosynthetic rate and stomatal conductance, increased $\mathrm{C}_{\mathrm{i}}$ in Al sensitive barley genotype XZ61. When concerning ROS scavenging systems, increase of CAT and APX activities under $\mathrm{Al}$ stress, might be correlated to $\mathrm{Al}$ tolerance mechanism in XZ16.

\section{ACKNOWLEDGEMENTS}

This study was financially supported by the National 863 program (2012AA101105) and the National Natural Science Foundation of China (30630047).

\section{REFERENCES}

1. L.V. Kochian, M.A. Pineros and O.A. Hoekenga, Plant Soil, 274, 175 (2005).

2. T.R. Guo, G.P. Zhang, M.X. Zhou, F.B. Wu and J.X. Chen, Pedosphere, 17, 505 (2007).

3. B.G. Du, H. Nian, Z.S. Zhang and C.Y. Yang, Acta Physiol. Plant, 32, 883 (2010).

4. S. Ali, P. Bai, F.R. Zeng, S.G. Cai, I.H. Shamsi, B.Y. Qiu, F.B. Wu and G.P. Zhang, Environ. Exp. Bot., 70, 185 (2011).
5. Z.Q. Zhao, J.F. Ma, K. Sato and K. Takeda, Planta, 217, 794 (2003)

6. S. Ishikawa, T. Wagatsuma, R. Sasaki and P. Ofei-Manu, Soil Sci. Plant Nutri., 46, 751 (2000).

7. A.H. Wang, Z.Y. Yu and Y. Ding, Comptes Rendus Biol., 332, 393 (2009).

8. H.X. Dai, W.N. Shan, J. Zhao, G.P. Zhang, C.D. Li and F.B. Wu, J. Plant Nutr. Soil Sci., 174, 952 (2011).

9. F.B. Wu, G.P. Zhang and P. Dominy, Environ. Exp. Bot., 50, 67 (2003).

10. Y. Zhen, L. Miao, J. Su, S.H. Liu, Y.L. Yin, S.S. Wang, Y.J. Pang, H.G. Shen, D.C. Tian, J.L. Qi and Y.H. Yang, J. Plant Nutr., 32, 1255 (2009).

11. Q.Y. Tang and M.G. Feng, Practical Statistics and its DPS Statistical Software Package, Agriculture Press, Beijing, China (1997).

12. K. Ohki, Crop. Sci., 26, 572 (1986).

13. I.H. Shamsi, K. Wei, G. Jilani and G.P. Zhang, J. Zhejiang Univ. Sci. $B, 8,181$ (2007).

14. N. Mihailovic, G. Drazic and Z. Vucinic, Photosynthetica, 46, 476 (2008).

15. P. Sharma and R.S. Dubey, Plant Cell Rep., 26, 2027 (2007).

16. L.N. Yin, J. Mano, S.W. Wang, W. Tsuji and K. Tanaka, Plant Physiol., 152, 1406 (2010)

17. A. Gaume, F. Machler and E. Frossard, Plant Soil, 234, 73 (2001).

18. T.B. Kinraide, J.F. Pedler and D.R. Parker, Plant Soil, 259, 201 (2004).

19. J.L. Yang, J.F. You, Y.Y. Li, P. Wu and S.J. Zheng, Plant Cell Physiol., 48, 66 (2007)

20. R. Cristancho, M.M. Hanafi, S. Omar and M.Y. Rafii, Plant Biol., 13, 333 (2011).

21. M. Dawood, F.B. Cao, M.M. Jahangir, G.P. Zhang and F.B. Wu, J. Hazard. Mater., 209, 121 (2012). 